\title{
Critical appraisal of the role of fingolimod in the treatment of multiple sclerosis
}

This article was published in the following Dove Press journal:

Neuropsychiatric Disease and Treatment

7 September 201 I

Number of times this article has been viewed

\author{
Clemens Warnke ${ }^{1,2}$ \\ Olaf Stüve ${ }^{3,4}$ \\ Hans-Peter Hartung' \\ Anna Fogdell-Hahn ${ }^{2}$ \\ Bernd C Kieseier' \\ 'Department of Neurology, Heinrich- \\ Heine-University, Düsseldorf, \\ Germany; ${ }^{2}$ Department of Clinical \\ Neuroscience, Karolinska Institute, \\ Stockholm, Sweden; ${ }^{3}$ Department \\ of Neurology, Dallas Veterans \\ Affairs Medical Center, TX, USA; \\ ${ }^{4}$ Department of Neurology, University \\ of Texas Southwestern Medical \\ Center at Dallas, TX, USA
}

\begin{abstract}
This review summarizes Phase III clinical trial data available for fingolimod. The main purpose is to evaluate the benefit-risk profile of fingolimod, the first oral compound available for treatment of multiple sclerosis (MS) and just recently approved by the European authorities. The authors place this evaluation in the context of the known safety and efficacy profile of established compounds for therapy of MS to outline the current and future potential of fingolimod. The authors conclude that only long-term safety data from post-marketing surveillance plans, together with additional head-to-head studies, would allow evidence-based treatment decisions. Furthermore, risk-profile analyses including patient history, exposure data to certain pathogens, and genetic analyses may potentially help to choose the right drug for individual patients in the future. Until these approaches toward an individualized medicine have been validated, treatment decisions for one or the other compound will have to be based partly on class IV evidence. Therefore, a close dialog with the well-informed patient, secured by effective risk mitigation plans, is required to choose the compound.
\end{abstract}

Keywords: FTY720, oral drug, spingosine 1-phosphate receptor

\section{Introduction}

Multiple sclerosis (MS) is a chronic and debilitating immune-mediated disease of the central nervous system (CNS). Recent epidemiological data supports the established view that the incidence of MS peaks at about 30 years of age and that it is a disease with a positive female-to-male ratio. ${ }^{1}$ Widespread axonal pathology has already been reported in early stages of MS, including clinically isolated syndrome (CIS). ${ }^{2,3}$ Thus, treatment initiation at an early stage in the disease seems crucial; this is supported by positive clinical trial data for first-line disease-modifying drugs (DMDs) in delaying conversion of CIS to MS in patients. ${ }^{4}$ Paraclinical surrogate parameters are currently under investigation to predict disease progression and conversion from CIS to MS, including magnetic resonance imaging (MRI) criteria at initial presentation and the presence of oligoclonal bands or levels of CXCL-13 in cerebrospinal fluid (CSF). ${ }^{3-5}$ However, these surrogates are not yet able to predict the future grade of disability on an individual basis with certainty. ${ }^{6}$ In the European Union (EU), the three different interferon-beta (IFN $\beta$ ) formulations available, as well as glatiramer acetate (GA), are considered as first-line treatments based on class I evidence for similar efficacy and a positive safety profile. ${ }^{7}$ Recent head-to-head studies did not detect differences in the primary endpoints between IFN $\beta$ and GA. When selecting a treatment from among these injectable drugs, individual decisions will be based mainly on the preferred route
Correspondence: Bernd C Kieseier

Department of Neurology,

Heinrich-Heine-University,

Moorenstrasse 5, D-40225

Düsseldorf, Germany

Tel +492118117079

Fax +492118116282

Email bernd.kieseier@uni-duesseldorf.de 
of application (subcutaneous or intramuscular [IM]) and the individual tolerability of the compound used.

Until recently, natalizumab was the established second choice for patients failing first-line DMDs. In addition, it has been approved as a primary treatment for patients with highly active relapsing-remitting MS (RRMS). Natalizumab is a humanized monoclonal IgG4 antibody, designed to target the alpha-4 integrin, and is most relevant for leukocyte migration across endothelial barriers. ${ }^{8,9}$ Class I evidence is available for superiority regarding clinical outcome measures of natalizumab compared with placebo and for the combination of natalizumab and IM IFN $\beta$-1a compared with IM IFN $\beta$-1a alone. ${ }^{10,11}$ However, no class I evidence is available directly comparing efficacy of natalizumab with first-line DMDs. When looking at the efficacy of natalizumab and first-line DMDs across different clinical trials on clinical outcome measures such as the annualized relapse rate (ARR), the data available suggest superiority of natalizumab; this is supported by clinical experience (class IV evidence). ${ }^{4}$ Therefore, restricted approval as a second-line treatment is not explained by inferiority compared with first-line DMDs or by study design of trials relevant for approval; it is explained mainly by the occurrence of cases of progressive multifocal leukoencephalopathy (PML) in around 1/1000 patients treated with natalizumab. ${ }^{12-15}$ The risk of this potentially lethal or highly disabling adverse event (AE) increases to up to $8.1 / 1000$ patients ( $95 \%$ confidence interval: 5.4-11.6/1000 patients) among a subset of patients with prior immunosuppressant treatment who have been treated with natalizumab for more than 2 years, and who show evidence of JC virus exposure as assessed by JC virus serology. ${ }^{16}$

Furthermore, mitoxantrone was licensed in 2002 for treatment of patients with secondary progressive MS or where progressive relapsing MS is failing or not tolerating previous immunomodulatory therapy. ${ }^{7}$ However, the risk of cardiomyopathy and secondary leukemia, overall observed in $1 / 250$ to $1 / 800$ patients treated, limits the use of this drug and makes it a third-line treatment for patients with relapsing forms of $\mathrm{MS}^{7}$

On September 22, 2010, the US Food and Drug Administration approved fingolimod $0.5 \mathrm{mg}$, a sphingosine 1-phosphate (S1P) receptor modulator, as the first oral medication for treatment of RRMS. ${ }^{17}$ In March 2011, the European Medicines Agency (EMA) approved fingolimod in Europe. However, the European authorities restricted the approval to patients with high disease activity despite treatment with IFN $\beta$ (nonresponder) and to patients with rapidly evolving RRMS. ${ }^{18}$ The EMA defined nonresponders to IFN $\beta$ as those having failed to respond to "normally at least one year of treatment of
IFN $\beta .{ }^{\prime 18}$ According to EMA recommendations, these patients should have experienced a minimum of one relapse in the previous year while on IFN $\beta$, and at least nine T2-hyperintense lesions in cranial MRI or at least one gadolinium-enhancing lesion, or should have had an "unchanged or increased relapse rate or ongoing severe relapses, as compared to the previous year." 18 The second group of patients with rapidly evolving severe RRMS was defined "by 2 or more disabling relapses in 1 year, and with one or more Gadolinium enhancing lesions on brain MRI or a significant increase in T2 lesion load as compared with a previous recent MRI." 18

Thus, a restricted approval in the EU is given for two compounds, natalizumab and fingolimod, available for the same indication: first-line therapy for highly active MS or second-line therapy in patients not tolerating or not responding to first-line DMDs. In this review, the authors give an overview of clinical trial efficacy and safety data available that is relevant for the approval of fingolimod by the US and the European authorities; the authors then evaluate the current and future potential of fingolimod within the treatment algorithms for MS.

\section{Fingolimod and its mode of action}

The molecular structure of fingolimod is shown in Figure 1. Fingolimod is derived from myriocin, which has been primarily isolated from Isaria sinclairii, a fungus used in traditional herbal medicine. ${ }^{19}$ Fingolimod is predominately metabolized in the liver by sphingosine kinase to the active metabolite fingolimod-phosphate. ${ }^{20}$ Knock-out studies in S1P receptordeficient mice suggest $\mathrm{S} 1 \mathrm{P}$ receptors as key receptors relevant to the therapeutic effects in experimental autoimmune encephalitis, an animal model of MS. Accordingly, fingolimod-phosphate binds to four of the five known $\mathrm{S} 1 \mathrm{P}$ receptors: $\mathrm{S}_{1} \mathrm{P}_{1}, \mathrm{~S}_{1} \mathrm{P}_{3}, \mathrm{~S}_{1} \mathrm{P}_{4}$, and $\mathrm{S}_{1} \mathrm{P}_{5}$. Expression of these receptors varies throughout tissues, being differently expressed on lymphocytes, in various different peripheral organs, and cells of the CNS or the peripheral nervous system. ${ }^{21}$ Coupling to $\mathrm{G}$ proteins, S1P receptors regulate complex processes such as growth and survival, cell motility, cell invasion, angiogenesis, and trafficking of immune cells. Upon binding (eg, to the membrane-bound cell surface $\mathrm{S}_{1} \mathrm{P}_{1}$ receptor) fingolimod-phosphate induces internalization of

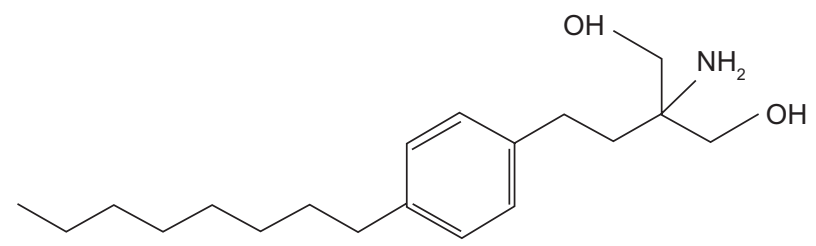

Figure I The chemical structure of fingolimod (2-amino-2-[2-(4-octylphenyl)ethyl] propan-1,3-diol hydrochloride). 
the receptor, which then leads to a sustained downregulation of the receptor on the gene expression level. ${ }^{22,23}$ In lymphatic tissue, fingolimod-phosphate thereby blocks the capacity of certain subpopulations of lymphocytes to egress lymph nodes, causing redistribution, rather than depletion, of lymphocytes. The redistribution of certain lymphocyte subpopulations is considered to reduce the infiltration of pathogenic cells into the CNS and to mediate the main therapeutic effect on the clinical course of MS. Naïve and memory T-cells, expressing the chemokine receptor CCR7 on their surface, are preferentially retained. In contrast, effector memory T-cells, which are capable of downregulating their surface CCR7, are less dependent on S1P signaling and thus are considered to preserve important immunological functions for antiviral or antineoplastic defense. ${ }^{21}$ In addition to reducing infiltration of pathogenic cells into the CNS, a direct neuroprotective and regenerative potential of fingolimod has been extensively discussed in recent literature. Fingolimod-phosphate is highly protein bound and is able to cross the blood-brain barrier. Thus, it could potentially directly interact with receptors on neurons and glia cells, and mediate the neuroregenerative effects proposed to be associated with fingolimod treatment. ${ }^{22}$ However, many of these immunological data derive from rodent models, ${ }^{24,25}$ and expression of $\mathrm{S} 1 \mathrm{P}$ receptors in a variety of different tissues may mediate not only its therapeutic but also its adverse effects so far observed in clinical trials. Overall, the lymphocyte count decreases to approximately $60 \%$ of baseline within 4-6 hours after the first dose, with normal counts usually reached within 1-2 months after treatment discontinuation. ${ }^{20}$

\section{Pharmacokinetics of fingolimod}

The oral bioavailability of fingolimod is $93 \%$ and the average terminal half-life is 6-9 days. ${ }^{20}$ As fingolimod is primarily metabolized by hepatic enzymes of the CYP family (mainly CYP4F2), inhibitors or inducers of these isozymes alter the exposure of fingolimod or fingolimod-phosphate. Patients with severe hepatic dysfunction should be closely monitored when receiving fingolimod as the risk of adverse reactions is potentially higher. ${ }^{20}$

\section{Efficacy of fingolimod in Phase III clinical trials Fingolimod vs placebo Study design}

Patients 18-55 years of age with RRMS ${ }^{26}$ and a score from 0 to 5.5 on the Expanded Disability Status Scale (EDSS) ${ }^{27}$ were eligible for the FTY720 Research Evaluating Effects of Daily Oral therapy in Multiple Sclerosis (FREEDOMS) double-blind clinical trial, which aimed to assess the efficacy of two different doses of oral fingolimod compared with placebo for 24 months. ${ }^{28}$ Prior to randomization, patients were required to have an active course of disease (one or more relapses in the previous year or two or more in the previous 2 years) and IFN $\beta$ or GA was to be stopped at least 3 months before the trial. Randomization was conducted in a 1:1:1 ratio to the high-dose (fingolimod $1.25 \mathrm{mg}$ ) or the low-dose (fingolimod $0.5 \mathrm{mg}$ ) treatment group or to placebo, each administered once daily. The primary clinical outcome measure was the ARR, defined as the number of confirmed relapses per year. A confirmed relapse needed to be associated with an increase of at least 0.5 points in the EDSS score, 1 point in each of two EDSS functional system (FS) scores, or 2 points in one EDSS FS score. The key secondary clinical outcome measure was time to confirmed disability progression after 3 months, as measured in an increase of 1 point in the EDSS score (or 0.5 points if the baseline EDSS score was 5.5) confirmed after 3 months. ${ }^{28}$ In addition, clinical endpoints (time to first relapse, time to disability progression after 6 months, changes in the EDSS score and the Multiple Sclerosis Functional Composite z-score between baseline and 24 months) and paraclinical endpoints (number of gadolinium-enhancing lesions, proportion of patients free from gadolinium-enhancing lesions, number of new or enlarged lesions on T2-weighted MRI scans, proportion of patients free from new or enlarged lesions on T2-weighted scans, volumes of hyperintense lesions on T2-weighted scans and hypointense lesions on T1-weighted scans, change in brain volume between baseline and 24 months) were assessed. ${ }^{28}$

\section{Study results}

In a total of 1033 patients completing the 24-month study, all clinical and paraclinical endpoints demonstrated superiority for both the low and the high dose of fingolimod over placebo. No significant differences in efficacy were observed when comparing the two different doses of fingolimod. Interestingly, the overall ARR observed in the fingolimod Phase III clinical trials was low compared with studies relevant for approval of interferons, for example. Thus, although the absolute reduction of the ARR appeared to be low, the relative reduction of the ARR (primary endpoint: 0.18 for fingolimod $0.5 \mathrm{mg}$; 0.16 for fingolimod $1.25 \mathrm{mg}$; 0.40 for placebo) compared with placebo was $54 \%$ and $60 \%$, respectively (Figure 2), independent of previous treatment with other DMDs. ${ }^{28}$ In addition, the percentage of patients without relapse was around $70 \%$ in the fingolimod $0.5 \mathrm{mg}$ group and $75 \%$ in the fingolimod $1.25 \mathrm{mg}$ group, compared 


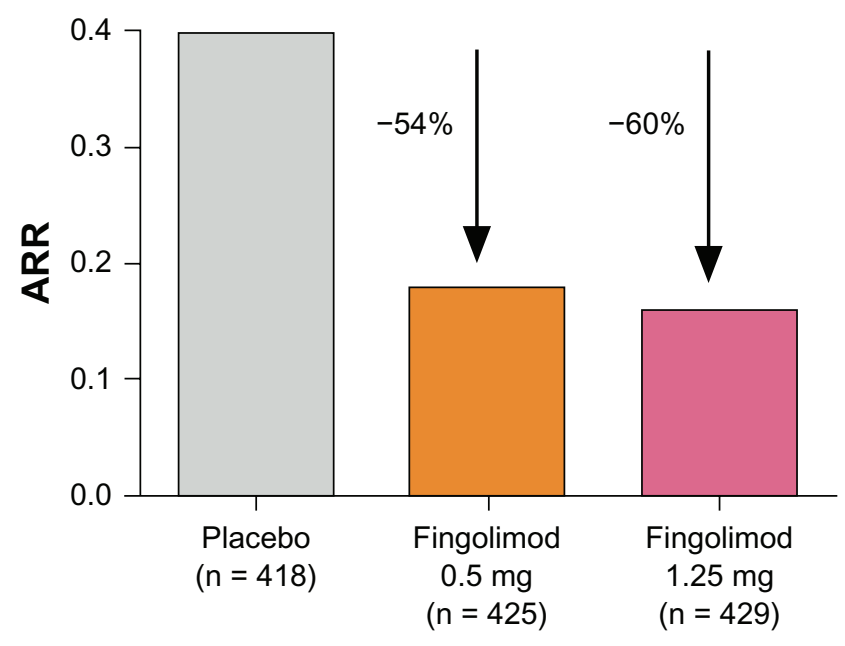

Figure 2 Annualized relapse rate (ARR) from baseline to month 24 in the FTY720 Research Evaluating Effects of Daily Oral therapy in Multiple Sclerosis (FREEDOMS) study. ${ }^{28}$

Notes: The percentages indicate the relative reduction of the ARR of fingolimod compared with placebo. Modified from Kappos L, Radue EW, O'Connor P, et al. A placebo-controlled trial of oral fingolimod in relapsing multiple sclerosis. $N$ Engl J Med. 2010;362(5):387-40I. ${ }^{28}$

with $46 \%$ in the placebo group. The key secondary outcome measure, the time to disability progression, confirmed after 3 months, demonstrated a hazard ratio for the risk of disability progression of 0.70 for the $0.5 \mathrm{mg}$ dose and 0.68 for the $1.25 \mathrm{mg}$ dose compared with placebo, showing that fingolimod may be able to delay disability progression. All paraclinical outcome measures were in favor of both of the treatment groups compared with placebo, including surrogates for inflammatory activity or scar formation on MRI (eg, number of contrast-enhancing lesions or number of new or enlarged lesions on T2-weighted scans), as well as measures for tissue loss (eg, change in volume of hypointense lesions on T1-weighted images or change in brain volume). ${ }^{28}$

\section{Fingolimod vs IFN $\beta$ Study design}

A 12-month, multicenter, randomized, double-blind, headto-head core study (Trial Assessing Injectable Interferon vs FTY720 Oral in Relapsing-Remitting Multiple Sclerosis [TRANSFORMS]) assessed the efficacy and safety of fingolimod compared with IM IFN $\beta-1 a^{29}$ Patients were randomized to receive either the high or the low dose of oral fingolimod once daily or IM IFN $\beta$-1a once a week as active comparator. The study was performed in a doubledummy fashion, with all patients receiving matching placebo in addition to the active treatment to ensure blinding. In a 12-month extension of the TRANSFORMS study, patients originally assigned to receive the high or the low dose of fingolimod continued with the same treatment, whereas patients originally receiving IFN $\beta$ - 1 a were re-randomized to either the high or the low dose of fingolimod. ${ }^{30}$ Inclusion criteria and definitions of outcome measures were similar to those described for the FREEDOMS study. The primary endpoint was the ARR. Time to confirmed disability progression and the number of new or enlarged hyperintense lesions on T2-weighted MRI scans were key secondary outcome measures. ${ }^{29}$

\section{Study results}

A total number of 1153 patients completed the core study, whereas 882 patients completed the total of 24 months on treatment including the extension phase. The primary outcome measure after 12 months showed superiority of both doses of fingolimod compared with IM IFN $\beta$-1a: there was a significantly greater reduction in the ARR (primary endpoint: 0.16 for fingolimod $0.5 \mathrm{mg}$; 0.20 for fingolimod $1.25 \mathrm{mg}$; 0.33 for IM IFN $\beta-1 \mathrm{a}$ ), with a relative reduction compared with IFN $\beta-1$ a of $52 \%$ and $38 \%$, respectively (Figure 3). ${ }^{29}$ Furthermore, patients initially randomized to receive IM IFN $\beta-1 \mathrm{a}$ in the core study demonstrated a lower ARR after switching to fingolimod (IFN $\beta-1$ a to fingolimod $0.5 \mathrm{mg}$ : ARR 0.31 [first year] vs 0.22 [second year]; IFN $\beta$-1a to fingolimod $1.25 \mathrm{mg}$ : ARR 0.29 [first year] vs 0.18 [second year]). The percentage of patients without relapse was $83 \%$

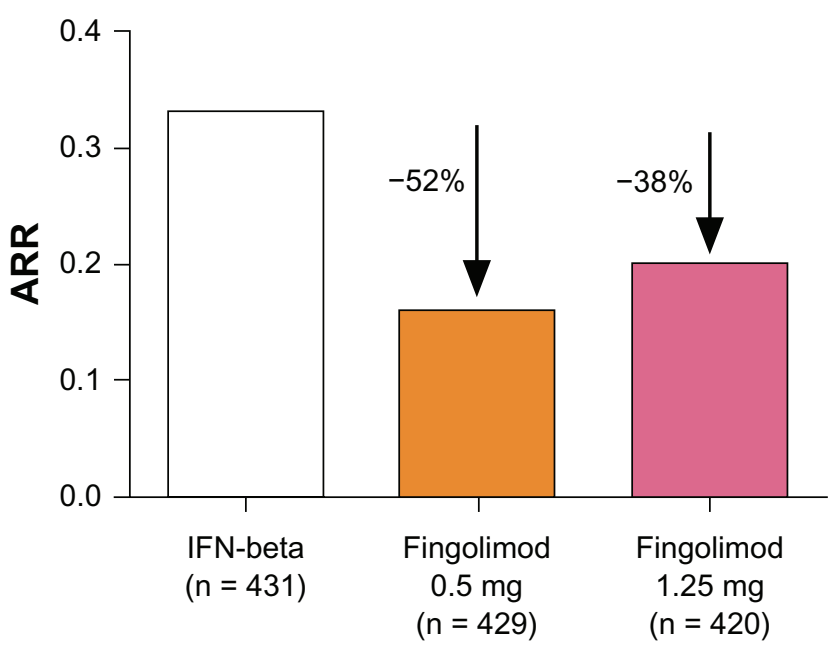

Figure 3 Annualized relapse rate (ARR) from baseline to month 12 in the Trial Assessing Injectable Interferon vs FTY720 Oral in Relapsing-Remitting Multiple Sclerosis (TRANSFORMS) study. ${ }^{29}$

Notes: The percentages indicate the relative reduction of the ARR of fingolimod compared with intramuscular interferon-beta- la (IFN $\beta$ Ia). Modified from Cohen JA, Barkhof F, Comi G, et al. Oral fingolimod or intramuscular interferon for relapsing multiple sclerosis. N Engl J Med. 2010;362(5):402-4I5. ${ }^{29}$ 
after 12 months in patients treated with fingolimod $0.5 \mathrm{mg}$, $80 \%$ for the fingolimod $1.25 \mathrm{mg}$ group, and $69 \%$ in the placebo group. In contrast to the FREEDOMS study, the TRANSFORMS study failed to show beneficial effects on disability progression. As TRANSFORMS was not designed to primarily demonstrate the beneficial effect of fingolimod on disability progression, this discrepancy could potentially be explained by the TRANSFORMS study being underpowered with an active comparator and a very low proportion of patients with disability progression overall in the study cohort. Regarding MRI outcome measures, patients in the two fingolimod groups demonstrated fewer new or enlarged hyperintense lesions on T2-weighted images at month 12 (mean: 1.7 for fingolimod $0.5 \mathrm{mg}$; 1.5 for fingoli$\bmod 1.25 \mathrm{mg} ; 2.6$ for placebo). Whereas the mean percent reduction in brain volume from baseline to 12 months was significantly reduced for the fingolimod groups, changes in the volume of lesions on unenhanced T2- or T1-weighted images at 12 months were similar among the different study arms. ${ }^{29}$ In this respect the results again differ from the FREEDOMS study data, most likely attributed to a lack of power as discussed for the disability progression.

\section{Ongoing phase III and IV clinical trials}

Currently, the search on ClinicalTrials.gov for the terms "fingolimod AND multiple sclerosis" lists 14 ongoing or planned clinical trials (Table 1). ${ }^{31}$ Among these, the extension trials, as well as post-marketing surveillance studies including a pregnancy registry, focus on long-term efficacy and safety of the approved low dose of fingolimod. The FTY720 in Patients With Primary Progressive Multiple Sclerosis study evaluates the efficacy of fingolimod in patients with primary progressive MS, and additional studies focus on biomarker changes during fingolimod treatment, the immune response during vaccination, or the beneficial effect of fingolimod on cognitive function compared with IFNß-1a (Table 1).

\section{Safety and tolerability of fingolimod}

Most of the safety data available derive from the two completed Phase III clinical trials, FREEDOMS and TRANSFORMS. Upper respiratory tract infections, headache, fatigue, nausea, and gastrointestinal dysfunction were among the most frequently observed AEs. ${ }^{28,29}$ As in previous clinical trial experience, dose-dependent decreases in the heart rate commencing 1 hour after the first dose of fingolimod were observed; thus, bradycardia and atrioventricular block were more frequently reported in patients receiving fingolimod than in controls. ${ }^{28,29}$ Therefore, according to the manufacturer's recommendations, patients are required to be observed for signs and symptoms of bradycardia for at least 6 hours after administration of the first dose. However, a recent report of a patient with MS who developed a delayed 7.5-second asystole and sustained bradycardia 21 hours after the first dose of fingolimod stresses the importance of cardiac monitoring during treatment initiation. ${ }^{32}$ This is of particular importance if additional risks for cardiac conduction abnormalities exist, such as risperidone comedication in the latter case mentioned. ${ }^{32}$ Within the clinical trials, the therapeutic low dose of fingolimod caused an increase of approximately $2 \mathrm{mmHg}$ systolic and $1 \mathrm{mmHg}$ diastolic blood pressure. Thus, blood pressure should be monitored throughout treatment with fingolimod.

Three deaths occurred in the FREEDOMS study: two in the placebo group (pulmonary embolism, traffic accident) and one in the high-dose fingolimod group (suicide). However, in the TRANSFORMS study, the two deaths observed both occurred in the high-dose fingolimod group: one due to disseminated primary varicella zoster infection (with corticosteroids as concomitant medication) and the other due to herpes simplex encephalitis. Two additional patients of this study arm died after the study (aspiration pneumonia, metastatic breast cancer). Infections were reported equally throughout the groups ( $69 \%-72 \%$ for FREEDOMS, $51 \%-53 \%$ for TRANSFORMS), with serious infections in $1.6 \%-2.6 \%$ and $0.2 \%-1.7 \%$ of patients, respectively. Bronchitis and pneumonia were more common in patients treated with fingolimod. ${ }^{28,29}$

Macular edema in patients treated with low-dose fingolimod occurred in $0.5 \%$ of patients in the TRANSFORMS study but did not occur for this dose in the FREEDOMS study. However, macular edema was more frequently observed in the high-dose fingolimod group ( $1 \%$ and $0.7 \%$, respectively). Patients with diabetes mellitus or history of uveitis seem to be at increased risk. Macular edema improved or resolved with or without treatment in most of the patients when the drug was discontinued. Nevertheless, some patients had residual visual acuity loss even after resolution. ${ }^{28,29}$

Modest dose-dependent reductions in forced expiratory volume over 1 second $\left(\mathrm{FEV}_{1}\right)$ and diffusing capacity of the lung for carbon monoxide were observed in patients treated with fingolimod, requiring spirometric evaluation if clinically indicated. 
Table I Ongoing Phase II-IV clinical trials: summary of ClinicalTrials.gov search results for the terms "fingolimod AND multiple sclerosis," selecting only ongoing or planned studies ${ }^{31}$

\begin{tabular}{|c|c|c|c|c|c|c|c|}
\hline Study & Phase & $\begin{array}{l}\text { Fingolimod } \\
\text { treatment } \\
\text { (mg) }\end{array}$ & Comparator & $\begin{array}{l}\text { Primary outcome } \\
\text { measure }\end{array}$ & Population & $\begin{array}{l}\text { Date results } \\
\text { expected }\end{array}$ & $\begin{array}{l}\text { ClinicalTrials. } \\
\text { gov ID }\end{array}$ \\
\hline FREEDOMS II & III & $0.5,1.25$ & Placebo & Safety and efficacy & RRMS & March 201I & NCT00355I34 \\
\hline INFORMS & III & $0.5,1.25$ & Placebo & Safety and efficacy & PPMS & December 2013 & NCT0073I692 \\
\hline $\begin{array}{l}\text { Extension } \\
\text { trials }\end{array}$ & $\mathrm{II}+\mathrm{III}$ & 0.5 & NA & $\begin{array}{l}\text { Long-term safety } \\
\text { and efficacy }\end{array}$ & RRMS & $\begin{array}{l}\text { February } 201 \mathrm{I}- \\
\text { April } 2014\end{array}$ & $\begin{array}{l}\text { NCT0I } 201356, \\
\text { NCT00662649, } \\
\text { NCT00670449, } \\
\text { NCT00235430, } \\
\text { NCT0I I } 27750\end{array}$ \\
\hline $\begin{array}{l}\text { Post-marketing } \\
\text { surveillance }\end{array}$ & Observ & 0.5 & NA & $\begin{array}{l}\text { Long-term safety } \\
\text { and efficacy }\end{array}$ & RRMS & December 2018 & NCT0I28I657 \\
\hline EPOC & IV & 0.5 & Standard care & Outcome and safety & RRMS & June 2012 & $\begin{array}{l}\text { NCTOI } 216072, \\
\text { NCT0I } 317004\end{array}$ \\
\hline Biomarker & III & 0.5 & NA & $\begin{array}{l}\text { Changes in immunological } \\
\text { biomarkers }\end{array}$ & RRMS & December 20II & NCT0I3I0I66 \\
\hline Vaccination & III & 0.5 & NA & $\begin{array}{l}\text { Immune response to } \\
\text { seasonal flu vaccination }\end{array}$ & RRMS & May 20II & NCT0II9986I \\
\hline $\begin{array}{l}\text { Pregnancy } \\
\text { registry }\end{array}$ & III & $0.5,1.25$ & NA & Pregnancy outcome & RRMS & April 2017 & NCT0I 285479 \\
\hline GOLDEN & III & 0.5 & IFNß-Ib & Cognitive symptoms & RRMS & June 2013 & NCT0I33350I \\
\hline
\end{tabular}

Abbreviations: EPOC, A 6 month, Randomized, Open-label, Patient OutComes, Safety and Tolerability Study of Fingolimod 0.5 mg/Day vs. Comparator in Patients With Relapsing Forms of Multiple Sclerosis; FREEDOMS II, FTY720 Research Evaluating Effects of Daily Oral therapy in Multiple Sclerosis; GOLDEN, Fingolimod Versus IFN Beta Ib in Cognitive Symptoms; ID, identifier; IFN $\beta$, interferon-beta; INFORMS, FTY720 in Patients With Primary Progressive Multiple Sclerosis; NA, not applicable; Observ, observational; RRMS, relapsing-remitting multiple sclerosis; PPMS, primary progressive multiple sclerosis.

Increases in liver enzymes such as alanine aminotransferase were more frequently observed in the treatment groups of the FREEDOMS and TRANSFORMS studies ( $8.5 \%$ and $8 \%$, respectively, for fingolimod $0.5 \mathrm{mg} ; 12.5 \%$ and $7 \%$, respectively, for fingolimod $1.25 \mathrm{mg} ; 1.7 \%$ for placebo; $2 \%$ for IFN $\beta$ ). ${ }^{28,29}$ In general, serum transaminase levels returned to normal within 2 months after treatment discontinuation.

Oral carcinogenicity studies in mice and rats with doses higher than the equivalent recommended human dose resulted in an increased incidence of malignant lymphomas. ${ }^{20}$ Malignancies occurring in patients treated with fingolimod within the FREEDOMS and TRANSFORMS core studies were basal cell carcinoma (ten cases in total), breast cancer (five cases), malignant melanoma (two cases), and Bowen's disease (one case); however, overall occurrence of malignancies did not differ between the fingolimod-treated patients and the control groups.

Data on teratogenicity and embryolethality in humans is limited, but fetal malformations including persistent truncus arteriosus and ventricular septal defect were observed in rats. Within the Phase II and III clinical trials, 47 pregnancies occurred and 15 healthy children were born. ${ }^{33}$ However, one case of tibia malformation was reported, five spontaneous abortions occurred, and 14 patients decided to undergo elective abortion (among these, one case of tetralogy of Fallot was seen). Acrania was detected by ultrasonography in one of the twelve pregnancies reported as still ongoing. ${ }^{33}$ Thus, due to the calculated elimination time, women of childbearing potential have to use effective contraception during and for 2 months after treatment discontinuation. ${ }^{20}$ In addition, a pregnancy registry has been initiated to monitor outcomes of pregnancies in patients treated with fingolimod.

\section{Conclusion and perspective: potential of oral fingolimod in treatment of MS}

There are obvious reasons why the approval of fingolimod should be highly appreciated by MS patients and their physicians: First, in one head-to-head clinical trial, ${ }^{29}$ fingolimod has been proven to be superior to approved first-line DMDs as regards efficacy. This seems to hold true also for patients initially treated with IM IFN $\beta-1 \mathrm{a}$ and then switched to fingolimod..$^{30}$ This is of particular relevance, as this will mimic clinical practice when fingolimod is given as a secondline treatment. ${ }^{34}$ Second, oral administration could potentially further improve treatment acceptance in patients (no evident lifestyle restrictions, no further self-injections with local adverse effects or flu-like symptoms, no risk of developing 
antidrug antibodies). This could increase the compliance rate with an additional positive effect on long-term outcome in the individual patient. ${ }^{35}$

However, as a new compound without any post-marketing experience from other fields or conditions, only long-term surveillance data after approval will allow us to judge the future position of fingolimod within the current treatment regimens for $\mathrm{MS}$.

The following two key questions are still to be answered before the treating neurologist is able to make evidence-based decisions: (1) Has fingolimod a positive benefit-risk ratio compared with the established first-line DMDs such as IFN $\beta$ or GA? or, in other words, considering the situation in the US: Can fingolimod equally be offered to the young and otherwise healthy patients of childbearing potential? (2) Considering the approval in the EU: which compound to choose for patients with highly active MS or patients not tolerating or not responding to first-line DMDs, natalizumab, or fingolimod?

With regard to the first question, we learned from natalizumab that phase III clinical trials are unable to predict the risk of rare complications such as PML. Targeting lymphatic $\mathrm{S} 1 \mathrm{P}_{1}$ receptor is considered to preferentially target naïve and central memory T-cells, sparing the effector memory T-cell population. ${ }^{36}$ This could potentially result in a selective mode of action targeting autoimmunity and preserving key responses of the adaptive immunity relevant for viral defence. ${ }^{37}$ However, these concepts and treatment rationales still have to be confirmed by data from the post-marketing period. The first data available on changes to the immune response and cellular composition of peripheral blood and CSF from patients in clinical trials indicate not only significant peripheral cell depletion in patients treated with fingolimod but also potential changes to the immune surveillance in the CNS; fingolimod seems to decrease the absolute cell counts in CSF compared with pretreatment values, but it also leads to a reversion of the CD4:CD8 ratio in the $\mathrm{CSF}^{38}$ a finding discussed previously as having potential relevance to the PML pathogenesis in MS patients treated with natalizumab. ${ }^{39}$ Vaccination studies imply that these changes to the adaptive immunity may be of clinical relevance; although a recent study was not suggestive for relevant differences of the humoral immune response to influenza vaccines in patients treated with fingolimod compared with placebo, ${ }^{40}$ data from studies involving healthy volunteers treated with fingolimod $0.5 \mathrm{mg}$ assessing immunogenicity of keyhole limpet hemocyanin and the 23-valent pneumococcal polysaccharide vaccine indicate a decrease of antigenspecific IgM titers by $91 \%$ and $25 \%$, respectively, and of IgG titers by $45 \%$ and $50 \%$, respectively. ${ }^{20}$ Therefore, the observation of serious herpes virus infectious complications in the TRANSFORMS study leading to death in two cases may not be by chance, ${ }^{29}$ although causality to the treatment with fingolimod still has to be established. Furthermore, data on teratogenicity is limited and although effective contraceptive measures are mandatory during and for 2 months after treatment discontinuation, cases of pregnancy in this cohort of patients will most likely occur, with uncertain consequences for the unborn child. So, will the benefits outweigh the risks in a long-term perspective of several decades of treatment in the individual patient? The honest answer is this is not known yet. However, the established safety profile of long-term IFNß or GA treatment is known. Therefore, in the authors' opinion, these issues will need to be discussed with the well-informed patient before considering fingolimod as a first-line choice in treatment of MS.

On the grounds of these considerations, the authorities in the EU restricted the approval of fingolimod to cases of highly active MS or patients not tolerating or not responding to first-line DMDs. However, this leads to a situation of two compounds approved in the EU for the same indication: natalizumab and fingolimod. Both have been proven to be highly effective, although direct comparative head-to-head clinical trials have not yet been undertaken. So, in regard to the second key question - which compound to choose for this indication, natalizumab or fingolimod? - again, the final decision will be based on benefit-risk considerations in the individual patient. The first prerequisite for an evidencebased decision for the individual is head-to-head clinical trials comparing the two compounds in efficacy. While these should be performed, they most likely will never be conducted. While only post-marketing experience will be able to demonstrate the safety profile of fingolimod, first attempts to stratify patients at risk of PML treated with natalizumab are on the way. These approaches may in the future lead toward an individualized medicine, where data from a patient's history, genetic factors such as HLA status, functional measures for the innate and adaptive immunity, and exposure to specific infectious agents (such as JC virus serology) could be taken into account to find the best treatment for the individual patient. Until these promising future tools are validated and have been proven to be applicable in daily clinical practice, the correct individual treatment decisions can only be found in dialog with the well-informed 
patient, supported by high standards of post-marketing safety surveillance programs.

\section{Acknowledgment}

A European Committee for Treatment and Research in Multiple Sclerosis fellowship stipend to CW supported this work.

\section{Disclosures}

$\mathrm{BCK}$ and $\mathrm{H}-\mathrm{PH}$ have received honoraria for lecturing, travel expenses for attending meetings, and financial support for research from Bayer HealthCare, Biogen Idec, Merck Serono, Novartis, sanofi-aventis, and Teva Neuroscience. AF-H has received unrestricted research support from Biogen Idec, Merck Serono, and Bayer Schering. OS and CW report no conflicts of interest in this work.

\section{References}

1. Koch-Henriksen N, Sorensen PS. The changing demographic pattern of multiple sclerosis epidemiology. Lancet Neurol. 2010;9(5):520-532.

2. Filippi M, Bozzali M, Rovaris M, et al. Evidence for widespread axonal damage at the earliest clinical stage of multiple sclerosis. Brain. 2003;126(Pt 2):433-437.

3. Calabrese M, Rinaldi F, Mattisi I, et al. The predictive value of gray matter atrophy in clinically isolated syndromes. Neurology. 2011;77(3):257-263.

4. Hartung HP, Montalban X, Sorensen PS, Vermersch P, Olsson T. Principles of a new treatment algorithm in multiple sclerosis. Expert Rev Neurother. 2011;11(3):351-362.

5. Khademi M, Kockum I, Andersson ML, et al. Cerebrospinal fluid CXCL13 in multiple sclerosis: a suggestive prognostic marker for the disease course. Mult Scler. 2011;17(3):335-343.

6. Chard DT, Geurts JJ. Predicting the development of multiple sclerosis: is gray matter a missing piece of the puzzle? Neurology. 2011;77(3):210-211.

7. Wiendl H, Toyka KV, Rieckmann P, Gold R, Hartung HP, Hohlfeld R. Basic and escalating immunomodulatory treatments in multiple sclerosis: current therapeutic recommendations. J Neurol. 2008;255(10):1449-1463.

8. Ransohoff RM. Natalizumab for multiple sclerosis. $N$ Engl J Med. 2007;356(25):2622-2629.

9. Rice GP, Hartung HP, Calabresi PA. Anti-alpha4 integrin therapy for multiple sclerosis: mechanisms and rationale. Neurology. 2005;64(8):1336-1342.

10. Rudick RA, Stuart WH, Calabresi PA, et al. Natalizumab plus interferon beta-1a for relapsing multiple sclerosis. $N$ Engl J Med. 2006;354(9):911-923.

11. Polman CH, O'Connor PW, Havrdova E, et al. A randomized, placebocontrolled trial of natalizumab for relapsing multiple sclerosis. $N$ Engl J Med. 2006;354(9):899-910.

12. Warnke C, Adams O, Gold R, et al. Progressive multifocal leukoencephalopathy under natalizumab. Initial possibilities for risk stratification? Nervenarzt. 2011;82(4):475-480. [German]

13. Warnke C, Menge T, Hartung HP, et al. Natalizumab and progressive multifocal leukoencephalopathy: what are the causal factors and can it be avoided? Arch Neurol. 2010;67(8):923-930.

14. Clifford DB, De Luca A, Simpson DM, Arendt G, Giovannoni G, Nath A. Natalizumab-associated progressive multifocal leukoencephalopathy in patients with multiple sclerosis: lessons from 28 cases. Lancet Neurol. 2010;9(4):438-446.
15. Yousry TA, Major EO, Ryschkewitsch C, et al. Evaluation of patients treated with natalizumab for progressive multifocal leukoencephalopathy. N Engl J Med. 2006;354(9):924-933.

16. Sandrock AHC, Richman S, Natarajan A, et al. Risk stratification for progressive multifocal leukoencephalopathy (PML) in MS patients: role of prior immunosuppressant use, natalizumab-treatment duration, and anti-JCV antibody status. Paper presented at: The 63rd Annual Meeting of the American Academy of Neurology; 2011 Apr 9-16; Honolulu, Hawaii.

17. US Food and Drug Administration (FDA). FDA approves first oral drug to reduce MS relapses [press release]. Sep 22, 2010. Available at: http://www.fda.gov/NewsEvents/Newsroom/PressAnnouncements/ ucm226755.htm. Accessed June 1, 2011.

18. European Medicines Agency (EMA). Assessment report: Gilenya. Doc Ref: EMA/108602/2011. February 17, 2011. Available at: http://www. ema.europa.eu/docs/en_GB/document_library/EPAR_-_Public_assess ment_report/human/002202/WC500104529.pdf. Accessed June 1, 2011.

19. Fujita T, Inoue K, Yamamoto S, et al. Fungal metabolites: Part 11, a potent immunosuppressive activity found in Isaria sinclairii metabolite. J Antibiot (Tokyo). 1994;47(2):208-215.

20. Novartis Pharmaceutical Corporation. Prescribing information. Available at: http://www.pharma.us.novartis.com/product/pi/pdf/ gilenya.pdf. Accessed June 1, 2011.

21. Hla T, Brinkmann V. Sphingosine 1-phosphate (S1P): physiology and the effects of S1P receptor modulation. Neurology. 2011;76 (8 Suppl 3): S3-S8.

22. Aktas O, Kury P, Kieseier B, Hartung HP. Fingolimod is a potential novel therapy for multiple sclerosis. Nat Rev Neurol. 2010;6(7): 373-382.

23. Matloubian M, Lo CG, Cinamon G, et al. Lymphocyte egress from thymus and peripheral lymphoid organs is dependent on $\mathrm{S} 1 \mathrm{P}$ receptor 1. Nature. 2004;427(6972):355-360.

24. Brinkmann V, Davis MD, Heise CE, et al. The immune modulator FTY720 targets sphingosine 1-phosphate receptors. J Biol Chem. 2002;277(24):21453-21457.

25. Mandala S, Hajdu R, Bergstrom J, et al. Alteration of lymphocyte trafficking by sphingosine-1-phosphate receptor agonists. Science. 2002;296(5566):346-349.

26. Polman CH, Reingold SC, Edan G, et al. Diagnostic criteria for multiple sclerosis: 2005 revisions to the "McDonald Criteria". Ann Neurol. 2005;58(6):840-846.

27. Kurtzke JF. Rating neurologic impairment in multiple sclerosis: an expanded disability status scale (EDSS). Neurology. 1983;33(11): 1444-1452.

28. Kappos L, Radue EW, O'Connor P, et al. A placebo-controlled trial of oral fingolimod in relapsing multiple sclerosis. $N$ Engl $J$ Med. 2010;362(5):387-401.

29. Cohen JA, Barkhof F, Comi G, et al. Oral fingolimod or intramuscular interferon for relapsing multiple sclerosis. $N$ Engl $J$ Med. 2010;362(5):402-415.

30. Khatri B, Barkhof F, Comi G, et al. Comparison of fingolimod with interferon beta-1a in relapsing-remitting multiple sclerosis: a randomised extension of the TRANSFORMS study. Lancet Neurol. 2011;10(6):520-529.

31. ClinicalTrials.gov [database online]. Bethesda, MD; US National Institutes of Health. Available at: http://clinicaltrials.gov/ct2/results? term=fingolimod+AND+multiple+sclerosis. Accessed June 1, 2011.

32. Espinosa PS, Berger JR. Delayed fingolimod-associated asystole. Mult Scler. 2011. In press.

33. Collins W, Francis G, Koren, et al. Lack of interaction between fingolimod (FTY720) and oral contraceptives, and pregnancy experience in the clinical program of fingolimod in multiple sclerosis. Paper presented at: The 63rd Annual Meeting of the American Academy of Neurology; 2011 Apr 9-16; Honolulu, Hawaii.

34. Kieseier BC, Wiendl H. Transforming multiple sclerosis trials into practical reality. Lancet Neurol. 2011;10(6):493-494. 
35. Turner AP, Williams RM, Sloan AP, Haselkorn JK. Injection anxiety remains a long-term barrier to medication adherence in multiple sclerosis. Rehabil Psychol. 2009;54(1):116-121.

36. Pinschewer DD, Brinkmann V, Merkler D. Impact of sphingosine 1-phosphate modulation on immune outcomes. Neurology. 2011 76 (8 Suppl 3):S15-S19.

37. Mehling M, Johnson TA, Antel J, Kappos L, Bar-Or A. Clinical immunology of the sphingosine 1-phosphate receptor modulator fingolimod (FTY720) in multiple sclerosis. Neurology. 2011;76(8 Suppl 3): S20-S27.
38. Kowarik MC, Pellkofer HL, Cepok S, et al. Differential effects of fingolimod (FTY720) on immune cells in the CSF and blood of patients with MS. Neurology. 2011;76(14):1214-1221.

39. Stüve O, Marra CM, Bar-Or A, et al. Altered CD4+/CD8+ T-cell ratios in cerebrospinal fluid of natalizumab-treated patients with multiple sclerosis. Arch Neurol. 2006;63(10):1383-1387.

40. Mehling M, Hilbert P, Fritz S, et al. Antigen-specific adaptive immune responses in fingolimod-treated multiple sclerosis patients. Ann Neurol. 2011;69(2):408-413.

\section{Publish your work in this journal}

Neuropsychiatric Disease and Treatment is an international, peerreviewed journal of clinical therapeutics and pharmacology focusing on concise rapid reporting of clinical or pre-clinical studies on a range of neuropsychiatric and neurological disorders. This journal is indexed on PubMed Central, the 'PsycINFO' database and CAS, and is the official

Submit your manuscript here: http://www.dovepress.com/neuropsychiatric-disease-and-treatment-journal journal of The International Neuropsychiatric Association (INA). The manuscript management system is completely online and includes a very quick and fair peer-review system, which is all easy to use. Visit http://www.dovepress.com/testimonials.php to read real quotes from published authors. 